\title{
Effects of biased information on the relationship between eyewitness confidence and accuracy
}

\author{
ROSALEEN H. RYAN and R. EDWARD GEISELMAN \\ University of California, Los Angeles, California
}

\begin{abstract}
The accuracy and confidence of observers' memories of a videotaped crime scenario were assessed. Seventy-six college undergraduates served as the subjects. One week after viewing the tape, the subjects read a passage that described the crime scenario, so as to "refresh their memories" of the event. The passage contained leading, misleading, or control (no supplemental) information. After reading the passage, the subjects were tested again. The results showed a significant interaction for accuracy between type of passage and time of test $(F=94.61, p<.001)$, and a significant interaction for confidence between type of passage, time of test, and type of response (correct, incorrect; $F=26.27, p<.001$ ). The overall pattern of findings indicated that the subjects spontaneously placed more confidence in the experimenter's biased knowledge of the event than in their own memories.
\end{abstract}

It has been shown reliably that biased information distorts the memories of eyewitnesses (Davis \& Schiffman, 1985; Harris, 1973; Loftus \& Zanni, 1975). In an experiment carried out by Loftus and Palmer (1974), questions that contained the term "smashed" were asked about an accident; these questions led to higher estimates of vehicle speed than did the same questions when they contained the term "hit." After a 1-week delay, the verb used in the question continued to have a significant effect on the eyewitnesses' responses. Loftus proposed that the memory of a complex event is composed of information that was perceived and retained at the time of the original event plus information that is supplied externally, at some point after the event. The information from both of these sources is said to be integrated as one "memory," and it becomes difficult to determine from which source a particular detail originated.

In a study by Geiselman, Fisher, Cohen, Holland, and Surtes (1986), subjects' accuracy was also shown to be affected by biasing information; and the effect of inconsistent information (misleading questions) on recall was greater than the effect of consistent information (leading questions). The lesser effect of the consistent information was attributed to approximately one half of the subjects' knowing the correct answers to the questions without the additional exposure to the correct information.

According to Smith and Ellsworth (1987), misleading questions are more likely to elicit false information from subjects when the questions are asked by a questioner who is perceived as knowledgeable. A witness must retain a sufficiently vivid memory of the events to contradict the misleading information, if the witness is to doubt the knowledgeable questioner. However, when the subjects

Requests for reprints should be addressed to R. E. Geiselman, Department of Psychology, University of California, 405 Hilgard Avenue, Los Angeles, CA 90024-1563. were informed that the interrogator was not knowledgeable about the facts, misleading questions produced no effect. In fact, when the subjects knew that the interrogator was naive, their accuracy was comparable to that of subjects who were not given misleading information.

A variable that has been of interest to the courts in regard to witness accuracy is confidence. Brigham, Maass, Snyder, and Spaulding (1982) found a moderate relationship between confidence and accuracy $(r=+.50)$. Eighty-five percent of the suspect identifications in which the subjects were certain to the extent of being willing to testify in court were correct. Most studies, however, have shown that confidence is only weakly related to accuracy. For example, Davis and Schiffman (1985) found that subjects who were asked leading questions containing possessive pronouns were more confident in their responses than were subjects who were asked questions containing indefinite articles, even for objects that did not exist. Lindsay, Wells, and Rumpel (1981) found that witnesses' confidence in suspect identifications did not decrease under conditions where the probability of making incorrect identifications was increased. Furthermore, witnesses who operated under low identification conditions were no less willing to be cross-examined.

The present study was designed to assess the effects of leading and misleading information on the relationship between confidence and accuracy in a witness's recall of an event. As noted above, the results of research addressing the effects of leading and misleading questions on accuracy have been reliable. The data concerning the relationship between accuracy and confidence are less conclusive.

\section{METHOD}

\section{Subjects}

The subjects were 76 undergraduate students enrolled in an introductory psychology course at the University of California, Los Angeles. They participated to fulfill a course requirement. 


\begin{abstract}
Materials
Crime scenario. Two training films that were borrowed from the Los Angeles Police Department were used. One of the films depicts a liquor store robbery that takes place at night on a street and in an alley. The other film depicts a family dispute that takes place during the day at a residence. Each film is approximately 3 min long.

Information passages. Six passages were constructed to present supplemental information to the subjects. Three of the passages pertained to the film of the liquor store robbery and the other three passages pertained to the film of the family dispute. For each film, one passage contained leading information, one passage contained misleading information, and the third served as a control passage. As an example, the first statement of the control passage for the family dispute read, "A police car is at a house." The corresponding leading statement read, "A police car is at a white house." The corresponding misleading statement read, "A police car is at a brown house." (The house was, in fact, white.)

Test forms. Two test forms were constructed. One form pertained to the tape of the liquor store robbery, and the other form pertained to the tape of the family dispute. Each form contained 20 questions, 10 of which were target questions. The other 10 questions were filler items. The target questions were randomly mixed with the filler items, with the requirement that no more than two target or filler questions appear consecutively. The questions were listed in the order corresponding to the chronology of events in the scenario. The target questions were aimed at leading, misleading, and neutral information presented in the leading, misleading, and control information passages, respectively.

Distractor tasks. Two distractor tasks were constructed, each of which contained six questions: three elementary algebra problems and three reasoning and logic problems.
\end{abstract}

\section{Procedure}

The subjects were randomly assigned to view one of the two crime scenarios. The subjects were told that they would be tested on their ability to perform reasoning tasks after watching a crime scenario. The subjects viewed the tape at a distance of $6 \mathrm{ft}$ from a 19-in. Sony Linytron color monitor. Following the tape, the subjects were given $15 \mathrm{~min}$ to complete the first set of distractor problems. Following completion of the distractor problems, the subjects were given the test form corresponding to the tape that they had just seen. The subjects were told to answer all questions and to guess on those about which they were unsure. The subjects also gave a confidence rating for each answer on a scale of 1 (very uncertain) to 5 (very certain).

One week later the subjects returned. They were given one of the three passages to read and were told that the purpose of the passage was to refresh their memories of what had happened in the film that they had seen 1 week earlier. The passage corresponded to the film that the subjects had viewed. The type of passage that they received-leading, misleading, or control-was randomly determined. After the subjects read the passage, they were given the second set of distractor problems and were told that they were being tested on their reasoning ability. The subjects were given $15 \mathrm{~min}$ to complete this set of distractor tasks. Then, the subjects were administered the same test form that they had received 1 week earlier.

\section{Design}

The experimental design produced a two-way data matrix, with the factors being type of information passage (between-subjects: leading, misleading, control) and time of test (within-subjects: before or after passage presentation). The dependent variables were accuracy and confidence. Accuracy was defined as the number of target questions answered correctly (out of 10 ). The average confidence rating was computed independently for the correct answers and the incorrect answers within each cell of the design for each subject.

\section{RESULTS}

\section{Accuracy}

The average number of questions answered correctly is presented in Table 1 as a function of type of information passage and time of test. The interaction between
Table 1

Number of Correct Answers and Average Confidence Rating for Correct and Incorrect Answers, As a Function of Type of Information Passage and Time of Test

\begin{tabular}{|c|c|c|c|c|c|}
\hline \multicolumn{6}{|c|}{ Time of Test } \\
\hline \multicolumn{3}{|c|}{ Before Passage } & \multicolumn{3}{|c|}{ After Passage } \\
\hline & \multicolumn{2}{|c|}{ Confidence Rating } & \multirow[b]{2}{*}{ Correct } & \multicolumn{2}{|c|}{ Confidence Rating } \\
\hline Correct & $\begin{array}{l}\text { Avg. } \\
\text { Corr. }\end{array}$ & $\begin{array}{l}\text { Avg. } \\
\text { Incorr. }\end{array}$ & & $\begin{array}{l}\text { Avg. } \\
\text { Corr. }\end{array}$ & $\begin{array}{l}\text { Avg. } \\
\text { Incorr. }\end{array}$ \\
\hline 5.36 & 4.29 & 2.13 & 2.00 & 3.91 & 2.31 \\
\hline 5.15 & 4.12 & 2.24 & 5.00 & 4.09 & 1.91 \\
\hline 5.08 & 4.17 & 2.41 & 7.77 & 2.90 & 4.14 \\
\hline
\end{tabular}

these two factors was found to be significant $[F(2,74)=$ $94.61, p<.001]$. A Tukey's posttest showed that subjects were equally accurate before the information passage was presented; but, as predicted, accuracy increased following a leading passage, remained unchanged following a control passage, and decreased following a misleading passage.

\section{Confidence}

The average confidence rating is presented in Table 1 as a function of type of information passage, time of test, and accuracy of answer. As is evident from inspection of Table 1, the three-way interaction between these three factors was significant $[F(2,74)=26.27, p<.001]$. Prior to the presentation of the information passages, the subjects were significantly more confident in their correct responses than in their incorrect responses $(p<.001)$. This outcome is consistent with the findings of Brigham et al. (1982). Following the information passages, the subjects also were more confident in their correct responses, but only when the information was not misleading. Given misleading information, the subjects became more confident in their incorrect responses than in their correct responses $(p<.05)$. Seventy-six percent of the subjects' incorrect answers were consistent with the information included in the misleading questions.

\section{Debriefing}

After the subjects were debriefed about the purpose for the study, some spontaneously verbalized that they had initially found the information in the misleading passage to contradict their memories and that they suspected it to be false. They said that they later accepted the information as true by rationalizing that the experimenter would not intentionally supply them with false information. Only one subject verbalized during the experiment that the information in the passage was different from that in the film.

\section{DISCUSSION}

These results illustrate that eyewitnesses can be easily misled, especially when they perceive other sources of information to be more credible than they are themselves (Smith \& Ellsworth, 1987). The implication is that an investigator should appear to be as naive as the witness concerning the details of a crime. While a positive relationship was found between subjects' confidence and accuracy, this was true only when misleading information was not supplied to the subject. In that special case, 
the subjects placed more confidence in the experimenter's biased knowledge of what happened than in their own memories.

\section{REFERENCES}

Brigham, J. C., MaAss, A., Snyder, L. D., \& Spaulding, K. (1982). Accuracy of eyewitness identifications in a field setting. Journal of Personality \& Social Psychology, 42, 673-681.

Davis, J., \& Schiffman, H. R. (1985). The influence of the wording of interrogatives on the accuracy of eyewitness recollections. Bulletin of the Psychonomic Society, 23, 394-396.

Geiselman, R. E., Fisher, R. P., Cohen, G., Holland, H., \& SURTES, L. (1986). Eyewitness responses to leading and misleading questions under the cognitive interview. Journal of Police Science \& Administration, 14, 31-37.

HARRIS, R. J. (1973). Answering questions containing marked and un- marked adjectives and adverbs. Journal of Experimental Psychology, 97, 399-401.

Lindsay, R. C. L., Wells, G. L., \& Rumpel, C. M. (1981). Can people detect eyewitness-identification accuracy within and across situations? Journal of Applied Psychology, 66, 79-89.

Loftus, E. F., \& PALMER, J. C. (1974). Reconstruction of automobile destruction: An example of the interaction between language and memory. Journal of Verbal Learning \& Verbal Behavior, 13, 585-589.

LofTUS, E. F., \& ZANNI, G. (1975). Eyewitness testimony: The influence of the wording of a question. Bulletin of the Psychonomic Society, 5, 86-88.

Smith, V. L., \& Ellsworth, P. C. (1987). The social psychology of eyewitness accuracy: Misleading questions and communicator expertise. Journal of Applied Psychology, 72, 294-300.

(Manuscript received May 12, 1990.)

\section{ATB Institute Announces 1989 Supplement to Gray Collection}

The Alvina Treut Burrows Institute, Inc., of Manhasset, New York, announces the availability of the 1989 Supplement to the microfiche edition of The William S. Gray Research Collection in Reading. The Gray Collection of reading research documents has been ranked by many experts as the most comprehensive compilation of current and retrospective published research in any domain in the field of education.

The new supplement has 912 titles and includes titles on literacy, whole language learning, parental involvement in teaching reading, and reading in the content areas, with many studies from world-wide sources included.

There are now a total of 21,642 titles in the entire reading research collection compiled by specialists from key journals, books, research reports, and monographs published between 1884 and 1989. The Collection, arranged by author and subject (and fully annotated), affords the user easy access to the full-text documents which are reproduced on $4 \times 6$ microfiche. The seven major topics covered are: general summaries of research in reading, teacher preparation and practice, sociology of reading, physiology and psychology of reading, teaching of reading, atypical groups, and linguistics. Additional components of the Gray Collection include an introduction to the Collection, instructions for using the Collection, an author alphabetical index, and guide separators for both the Author/Chronological Index and the Subject Index.

A CD/ROM covering all titles is now in production.

This microfiche edition of the Collection has been produced by the Alvina Treut Burrows Institute, Inc. Dolly Svobodny serves as Executive Editor of the Collection and Warren Born is Special Consultant.

For further information, contact Dolly Svobodny, Alvina Treut Burrows Institute, Inc., Box 49, Manhasset, NY 11030-(516)869-8457. 